\title{
Formulation And Characterization Of Low Explosives From Palm Kernel Shell And Malaina Wood
}

\author{
* Oa Babatunde * Dr Hassan and *MM Namadi \\ Department Of Chemistry, Nigerian Defence Academy (NDA) Kaduna \\ DOI: 10.29322/IJSRP.12.01.2022.p12122 \\ http://dx.doi.org/10.29322/IJSRP.12.01.2022.p12122
}

\begin{abstract}
Low explosive propellants were formulated by using Palm kernel shell and Malaina wood as plant biomass using the Ammonium nitrate, Biomass (Carbon), Sulphur, Starch and Gum Arabic as binders in ratio of 80:16:2:2, 65:20:12:3 and 85:10:4:1 by mechanical means using mortar and pestle. The low explosives formulated were characterized using Scanning Electron Microscope (SEM), Fourier Transform Infrared (FTIR) and Differential Scanning colorimeter (DSC).The results of the FTIR confirmed interaction between the individual components by showing the presence of C-O stretch, N-O stretch, N-H Stretch, OH Stretch, N=C=S Stretch, within spectral ranges of $3908.1 \mathrm{~cm}^{-1}$ $-674.6 \mathrm{~cm}^{-1}$.SEM images indicated formation of low explosives with dimensions ranging from $58.3 \mu \mathrm{m}-4.75 \mu \mathrm{m}$, with morphological characteristics of white spheroidal substances, scraggy and crack at the surface. The DSC shows burning ability of the explosives tested covered distance that ranged from $588 \mathrm{~m}-$ $521 \mathrm{~m}$ which confirmed the explosive ability of the propellants formulated.
\end{abstract}

Index Terms- Low Explosives, Formulation, Microscope, Images.

\section{INTRODUCTION}

A $\mathrm{n}$ explosive (or explosive material) is a reactive substance that contains a great amount of materials that detonate as low or high explosive according to its rate of combustion (Jai, 2010). Low explosives are mixtures of chemicals that burn very rapidly but subsonically (deflagrating) and consist of fuel and oxidizer. The black powder is one of the examples of a low explosive. Under certain conditions such as the use of large quantities and a high degree of confinement, some normally deflagrating explosives can be used to detonate (Norman, 1998) These explosives exhibit many properties that are of interest to scientist and this led to different research on synthesis and characterization of low explosives to evaluate their properties for optimal performance (Niklos, 2004). The solid explosive is more stable and easily kept for storage than the liquid which is more cumbersome and difficult to control and mostly used for rocket purposes (Tenny, 1998).

Low explosives are widely used in gun and rocket propulsion applications. They are very energetic and produce high temperature gaseous products on combustion. The energy produced by a unit volume of a explosive is called its energy density. The high material density of these explosives leads to high energy density needed for producing the required propulsive force. (Moulai et al., 2016). Most of the explosives used by the Armed

This publication is licensed under Creative Commons Attribution CC BY.

http://dx.doi.org/10.29322/IJSRP.12.01.2022.p12122
Forces of Nigeria are being imported into the country. It is in the light of this that this study looks inward by using local carbon (biomass) sourced from different plants within the country, in order to formulate low explosives that could serve as alternatives.

\section{MATERIALS AND METHOD}

\section{SAMPLE COLLECTION}

The palm kernel shell was collected in a basket from Idah, Kogi state where the palm oil plantation is sited while Malaina wood was obtained within the residential area of Jibiya close, Barnawa Kaduna, where it is located abundantly. The gum arabic was collected from acacia trees (acacia segalis) in Maigatari, Jigawa State and the starch flour was sourced from cassava obtained from the open market. The collected samples were taken to a botanist in the Department of Biological Sciences, NDA Kaduna for identification and authentication.

\section{SAMPLE PREPARATION}

The Malaina wood was chopped off into smaller pieces using axe and the pieces of the wood were kept to dry at room temperature for a week. The dried pieces were collected in plastic bags and labeled before charring. The collected palm kernel shell was subjected to washing in order to remove the oil and was kept to dry at room temperature. The Gum Arabic binder was made from Gum sap (Gum Arabic) that was collected, dried and grinded into powder using mortar and pestle and later sieved using 15 micron size pores sieve and was kept in a plastic bottle. The starch binder was sourced from cassava which was peeled, washed and then grinded into paste with a grinding machine. The paste was collected into a clean bowl and allowed to settle for 3 hours, decanted and spread on a wide bowl to dry for 24 hours at room temperature to obtain the starch binder.

\section{Charring of Samples}

The charring was carried out using an air tight Germany Muffle Furnace with Model Number SXL 1006 set at $400{ }^{\circ} \mathrm{C}$ for one hour for Malaina wood while palm kernel was charred for two hours as reported by David et al., (2014). The prepared samples of the plants were weighed separately $(400 \mathrm{~g})$ in crucibles and introduced into muffle furnace chamber set at temperature of 250 ${ }^{0} \mathrm{C}$ for charring for one hour. On completing the charring, the furnace was switched off and allowed to cool for several hours before the charcoal was obtained. For the palm kernel shell, the temperature of the muffle furnace was set for $400{ }^{\circ} \mathrm{C}$ for two hours to obtain the charcoal. The charcoals were then grinded 
into powdered form separately using mortar and pestle and labeled separately, kept in sealed containers.

\section{Formulation of Low Explosives}

Low explosives were formulated from Palm kernel shell and Malaina wood as carbon sources according to ratios of Tenny $(65: 20: 12: 3)$, Cohen $(80: 16: 2: 2)$ and proposed $(85: 10: 4: 1)$ where ammonium nitrate (AN), carbon, sulphur and starch were weighed and transferred into motar and mixed thoroughly. The weights of these individual components were measured and mixed in such away to achieve ratios; 65:20:12:3, 80:16:2:2 and $85: 10: 4: 1$

\section{Characterization of the formulated low explosives (i) Scanning Electron Microscope (SEM)}

The images of the formulated explosives were carried out using Phenomenon PROX with model number 4.5.3. A $1.0 \mathrm{~g}$ of the pulverized formulated explosives samples were smeared on the stud housing the double adhesive carbon. The formulated explosives samples stud was placed in the sample holder and run for 5 seconds, a prompt sound signified the formulated explosives sample was ready for imaging. The images were adjusted for sharpness and clarity thereafter saved and printed.

\section{(ii) Fourier Transform Infrared Spectrometer (FTIR)}

FTIR characterization of the formulated explosives was done using the Agilent Carry FTIR Spectrometer (USA) with model number 630 where absorbance spectra were acquired over a range of $400-4000 \mathrm{~cm}^{-1}$ using DTGS detector.

One gram $(1 \mathrm{~g})$ of each of the formulated explosives samples was measured separately and fixed in a small cup like holder and compressed to pellet which was put on the crystal optical path and clicked on the software to process for proper sampling and coding of the formulated explosive samples and the peaks generated were labeled, saved and printed.

\section{(iii) Differential Scanning Calorimeter (DCS)}

One gram ( $1 \mathrm{~g})$ of the formulated explosives were measured into crucibles and introduced into the sample holder compartment of the machine (Model DSC2* MERTTNER TELEDO). The explosive samples were run between $30-500^{\circ} \mathrm{C}$ for the thermal analysis giving the transition phase, endothermic and exothermic readings and the results (graphic) were saved and printed.

\section{ROCKET DESIGN}

A PVC pipe of full length was reduced to the length of $300 \mathrm{~mm}$, with diameter of $48 \mathrm{~mm}$ in line with the rocket tube diameter system. The fin diameter for the rocket was obtained using aluminum sheet of $0.5 \mathrm{~mm}$ thickness which was cut to a required measurement of $50 \mathrm{x} 48 \mathrm{~mm}$.

A cone height of $50 \mathrm{~mm}$ diameter by $40 \mathrm{~mm}$ was obtained by using Plaster of Paris (POP) which was molded using a mold to the required cone shape. (Lostoski et al., 2016)

The explosives formulated according to their ratios using the charred plant biomass of APKS, BPKS, CPKS, AMWGA, BMWGA and CMWGA were used. The samples (400g) each were measured and formed into the hallow tube geometry and was made into 6 different geometric measurements according to the explosive ID selected based on the results of the DSC. After the compression, it was then allowed to dry at room temperature. The ignition system was designed using a cable with the two ends soldered to the filament containing an ignition charge which was made thicker and then connected to a match composition with a power source (battery) which allowed flow of current that ignited the explosives.

\section{Results and Discussion}

\section{Physical Properties of formulated Low Explosives}

The low explosives from Malaina wood was observed to be solid black powder with porous white patches on their surfaces, dark brownish and soft while the one from for palm kernel shell was homogenous powder black greyish with white patches.

\section{CHEMICAL CHARACTERIZATION}

\section{Fourier Transform Infrared (FTIR)}

The FTIR results of APKS, BPKS and CPKS (Fig 1) with different ratios A:B:C and APKGA, BPKGA and CPKGA (Fig 2) exhibited $\mathrm{O}-\mathrm{H}, \mathrm{N}-\mathrm{H}, \mathrm{C}=\mathrm{O}, \mathrm{N}=\mathrm{O}, \mathrm{N}=\mathrm{C}=\mathrm{S}$ and $\mathrm{C} \equiv \mathrm{C}$ vibrational stretchings within the ranges of $3851 \mathrm{~cm}^{-1}-1407.7 \mathrm{~cm}^{-1}, 3034.6$ $\mathrm{cm}^{-1}-1753.7 \mathrm{~cm}^{-1}, 1507 \mathrm{~cm}^{-1}-1407.1 \mathrm{~cm}^{-1}$ and $2329.6 \mathrm{~cm}^{-1}$ $1720.2 \mathrm{~cm}^{-1}$ respectively. The spectra observed were common to all other low explosive samples except for the presence of nitriles, which is unique to the formulated sample (CPKS). The FTIRresults of the study agree with the Tenny's (1998) findings on the formulation of low explosives.

The FTIR results of AMWS, BMWS and CMWS (Fig3) represent different ratios $\mathrm{A}: \mathrm{B}: \mathrm{C}$ and AMWGA, BMWGA, CMWGA (Fig 4) exhibited vibrational stretching such as $\mathrm{O}-\mathrm{H}, \mathrm{N}-$ $\mathrm{H}, \mathrm{C}=\mathrm{O}, \mathrm{N}=\mathrm{O}$ and $\mathrm{N}=\mathrm{C}=\mathrm{S}$ among other vibrational stretchings within the range of $3908.1 \mathrm{~cm}^{-1}-3600.6 \mathrm{~cm}^{-1}, 3269.2 \mathrm{~cm}^{-1}-3058$ $7 \mathrm{~cm}^{-1}, 1751.8 \mathrm{~cm}^{-1}-825.6 \mathrm{~cm}^{-1}, 1576.7 \mathrm{~cm}^{-1}-1302.7 \mathrm{~cm}^{-1}$, $2206.6 \mathrm{~cm}^{-1}-1653.4 \mathrm{~cm}^{-1}$ and $2346.4 \mathrm{~cm}^{-1}-1653.4 \mathrm{~cm}^{-1}$. These values observed fall within range of values reported by Rodrigo et al (2005) on formulation of explosives. These spectra observed were common to all formulated sample except for the presence of nitriles in BMWS.

On comparing the synthesized explosives with that of Gordana et al., (2006), using Ammonium Per chlorate AP and 1,3,5- Trisubstituted Isocyanurates universal binder indicated to be different in terms of the FTIR spectral. The AP synthesized displayed an $\mathrm{OH}=$ Stretching at 3486,3255 and $3137 \mathrm{~cm}^{-1}$ while for the AN synthesized from plant biomass gave a $\mathrm{OH}=$ Stretch at $3841,3632,3455.2 \mathrm{~cm}^{-1}$. For AP synthesized explosives by Gordana et al., (2006) exhibited a C=O Stretching of 709 and $699 \mathrm{~cm}^{-1}$ while that of the AN from plant biomass gave a single bond C-O Stretch 1291.5, 1043.8, $1041 \mathrm{~cm}^{-1}$. For N-H Stretching for the AP explosive gave $3137 \mathrm{~cm}^{-1}$ while the synthesized AN explosive gave 3231.6, 3052.2,2104.1, 2115.3, $1686.6 \mathrm{~cm}^{-1}$. These differences could be attributed to the different binders used where the AP explosive used a polymer binder while AN used Starch and Gum Arabic binders. The range of the FTIR results for various ratios used for the formulation of low explosive agreed with National America Space Agency (NASA) standard. 


\section{Agilent Technologies}

Sample ID:DANLADI HASSAN APKS 65- 20- 12- Method Name:Transmittance 3

Date/Time:2018-11-26T07:51:16.732-08:00

File Location:C:Program Files\AgilentlMicroLab PCIResultsIDANLADI HASSAN APKS 65- 20-123_2018-11-26T07-51-16.a2r

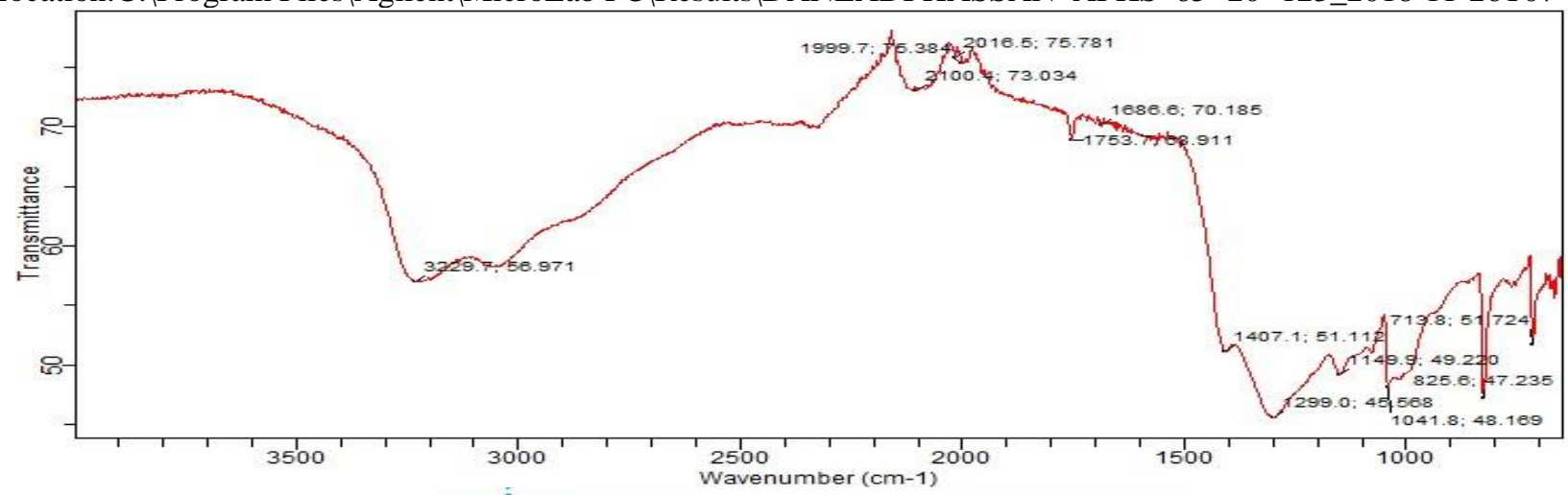

Agilent Technologies

Sample ID:DANLADI HASSAN BPKS 80-16- 2-2 Method Name:Transmittance Date/Time:2018-11-26T06:56:54.98-08:00

File Location:C:IProgram Files\AgilentlMicroLab PCIResultsIDANLADI HASSAN BPKS 80- 16- 22_2018-11-26T06-56-54.a2r

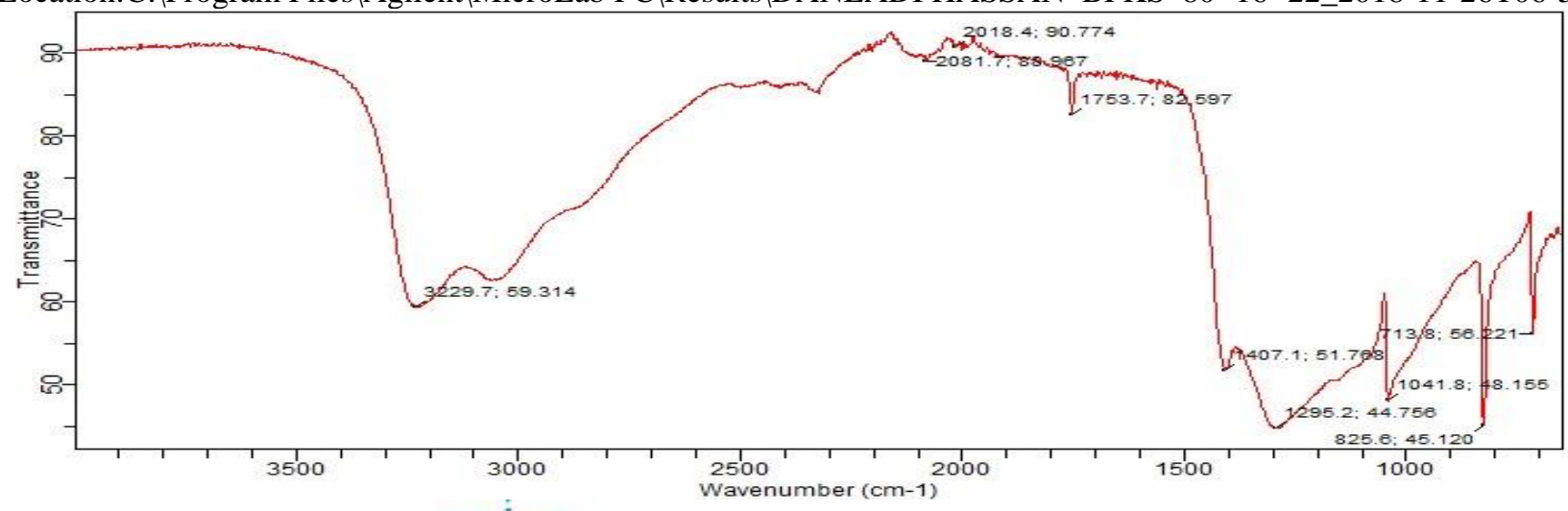

Agilent Technologies

Sample ID:DANLADI HASSAN CPKS 85- 10- 4-1 Method Name:Transmittance Date/Time:2018-11-26T06:14:29.261-08:00

File Location:C:IProgram Files\Agilent|MicroLab PCIResults\DANLADI HASSAN CPKS 85- 10- 41_2018-11-26T06-14-29.a2r

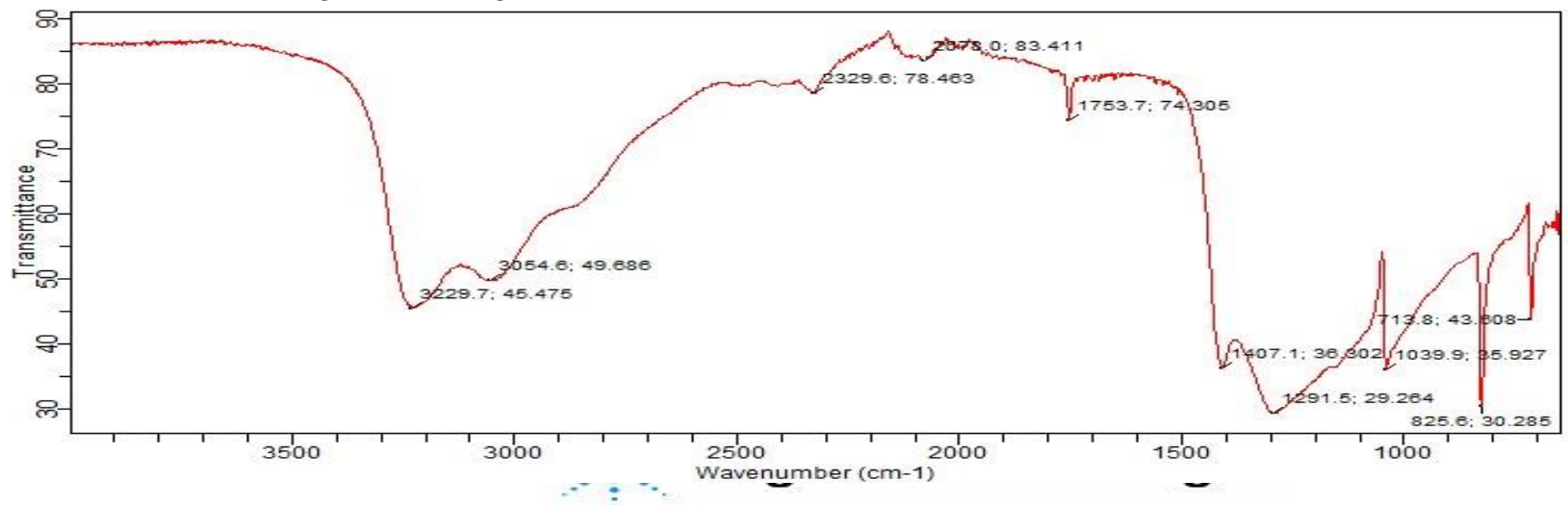

Sample ID:DANLADI HASSAN APKGA 65- 20- Method Name:Transmittance 12-3 Date/Time:2018-11-26T07:47:02.218-08:00

File Location:C:IProgram Files\AgilentlMicroLab PCIResults\DANLADI HASSAN APKGA 65- 20-123_2018-11-26T07-47-02.a2r 


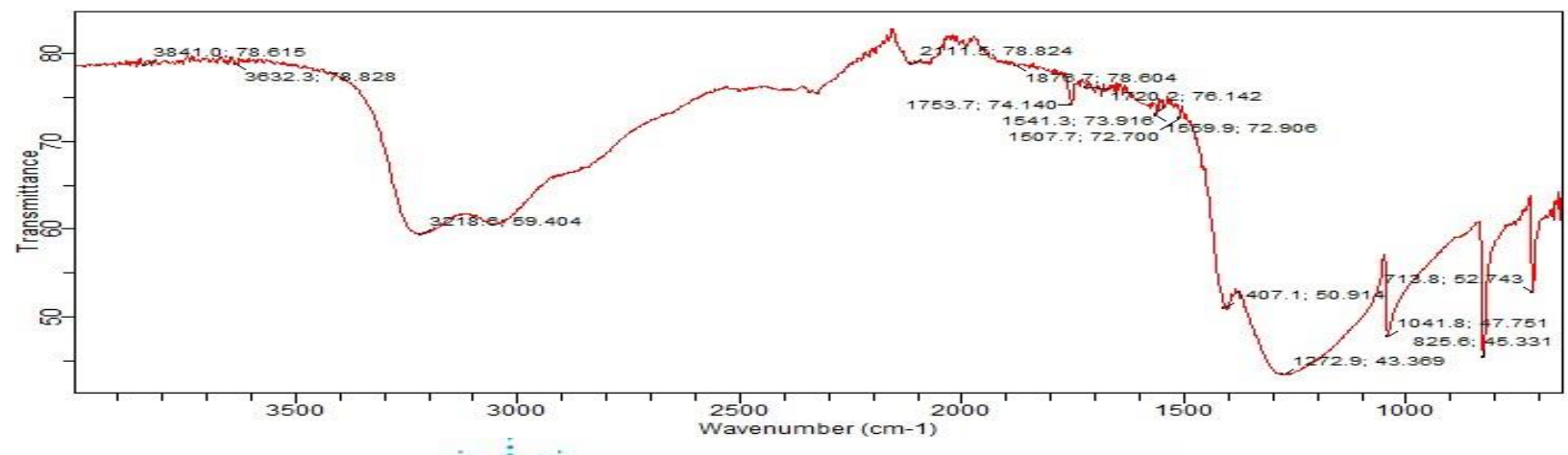

Agilent Technologies

Sample ID:DANLADI HASSAN BPKGA 80- 16- 2- Method Name:Transmittance

Date/Time:2018-11-26T07:11:32.684-08:00

File Location:C:IProgram Files\AgilentlMicroLab PCIResults\DANLADI HASSAN BPKGA 80- 16-22_2018-11-26T07-11-32.a2r

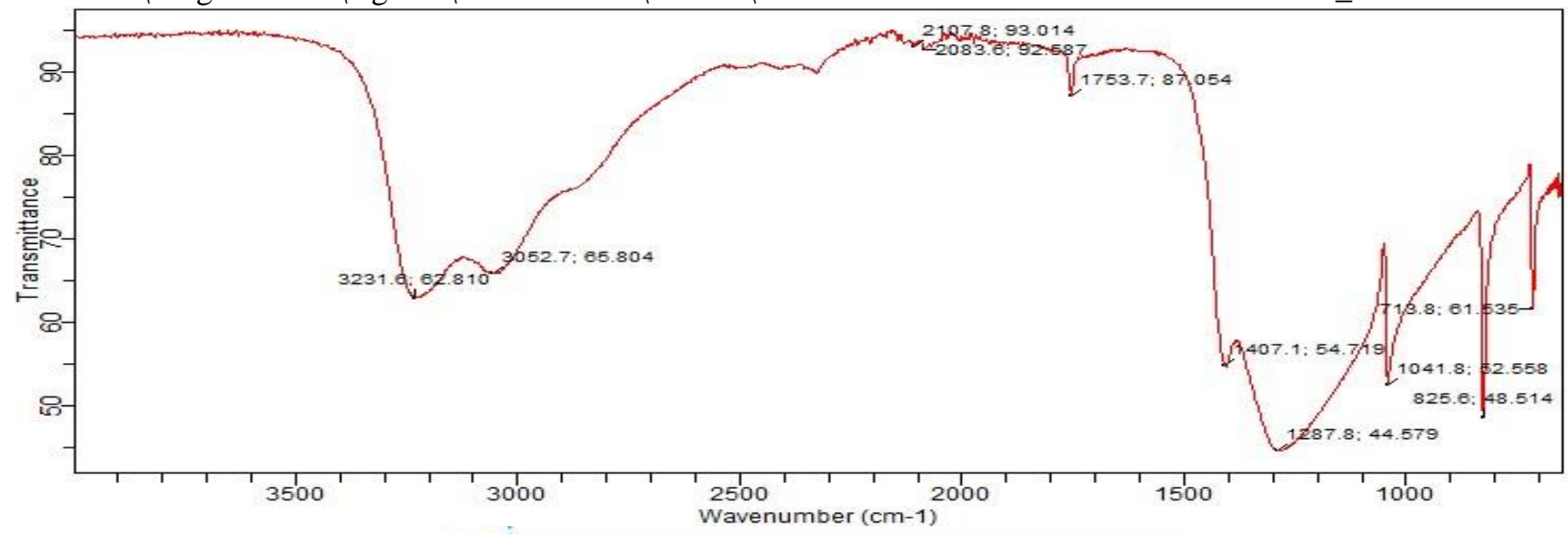

Agilent Technologies

Sample ID:DANLADI HASSAN CPKGA 85- 10- 4- Method Name:Transmittance 1

Date/Time:2018-11-26T06:22:40.038-08:00

File Location:C:IProgram Files\AgilentlMicroLab PCIResults\DANLADI HASSAN CPKGA 85- 10- 41_2018-11-26T06-22-40.a2r

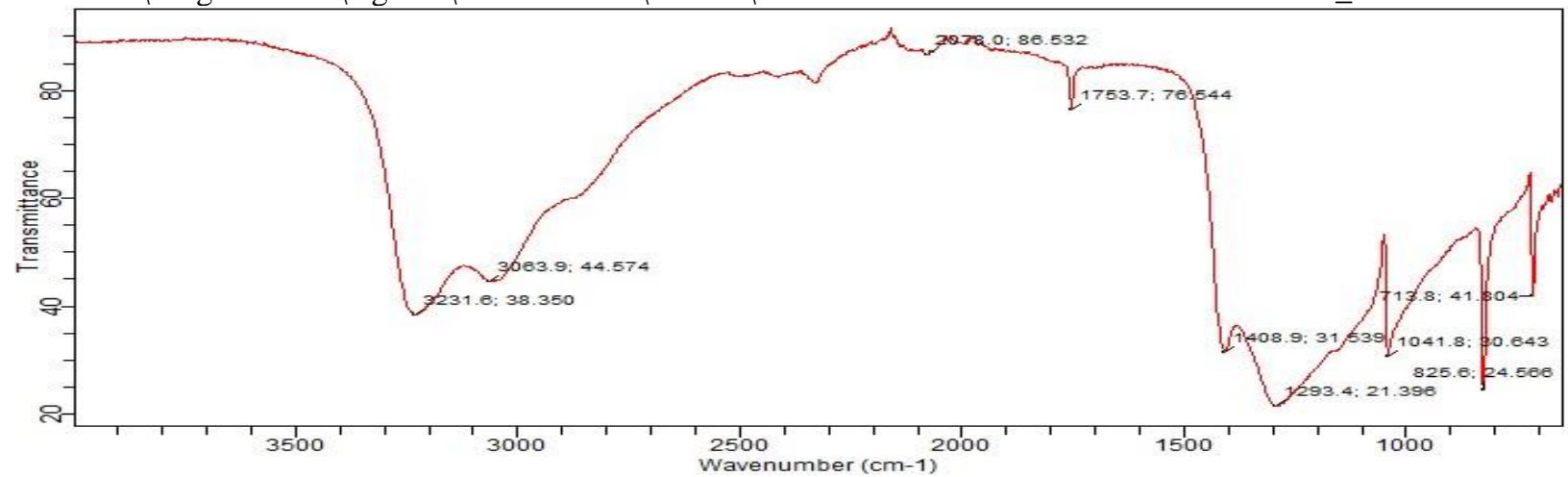

Agilent Technologies

Fig 2: FTIR Spectral of Explosives Samples of APKGA, BPKGA and CPKGA

Sample ID:DANLADI HASSAN AMWS 65- 20- 12- Method Name:Transmittance 3

Date/Time:2018-11-26T07:43:36.328-08:00

File Location:C:IProgram Files\AgilentlMicroLab PC\Results\DANLADI HASSAN AMWS 65- 20- 123_2018-11-26T07-43-36.a2r 


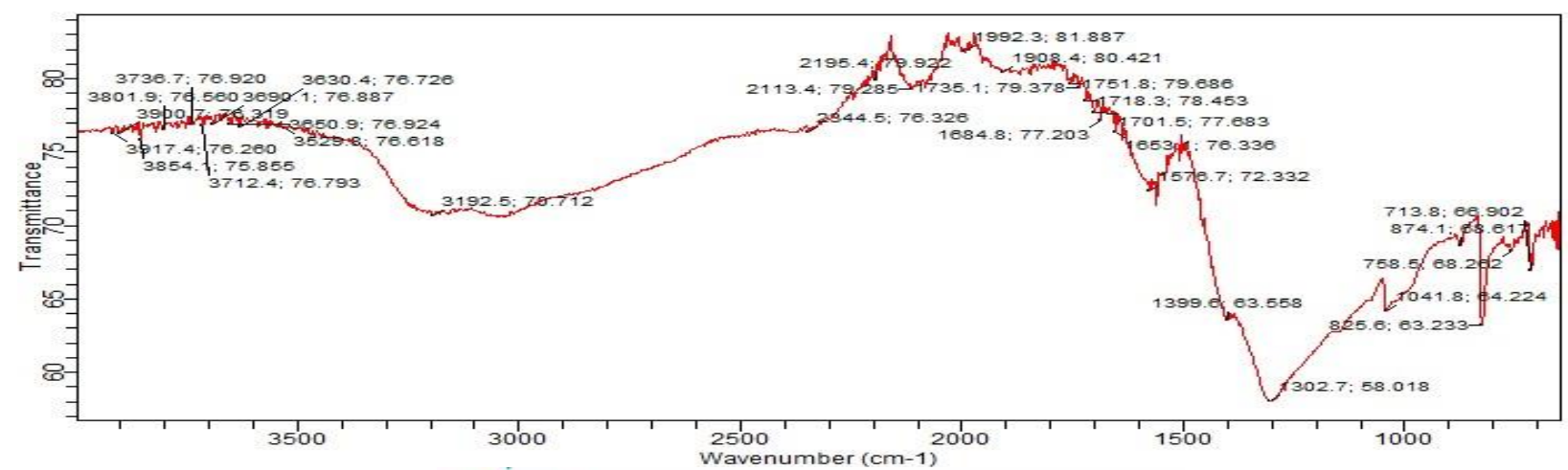

Agilent Technologies

Sample ID:DANLADI HASSAN BMWS 80- 16- 2-2 Method Name:Transmittance

Date/Time:2018-11-26T06:58:43.712-08:00

File Location:C:IProgram Files\AgilentlMicroLab PCIResults\DANLADI HASSAN BMWS 80- 16- 22_2018-11-26T06-58-43.a2r

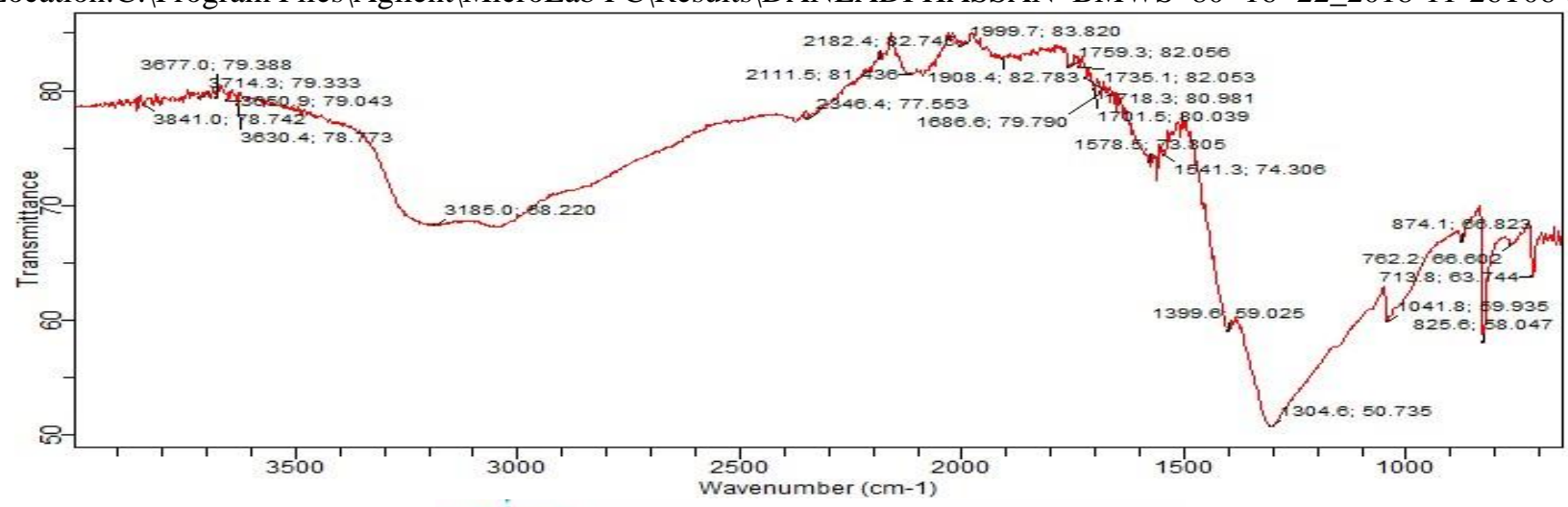

Agilent Technologies

Sample ID:DANLADI HASSAN CMWS 85- 10- 4-1 Method Name:Transmittance

Date/Time:2018-11-26T06:38:36.894-08:00

File Location:C:IProgram Files\AgilentlMicroLab PC\Results\DANLADI HASSAN CMWS 85- 10- 41_2018-11-26T06-38-36.a2r

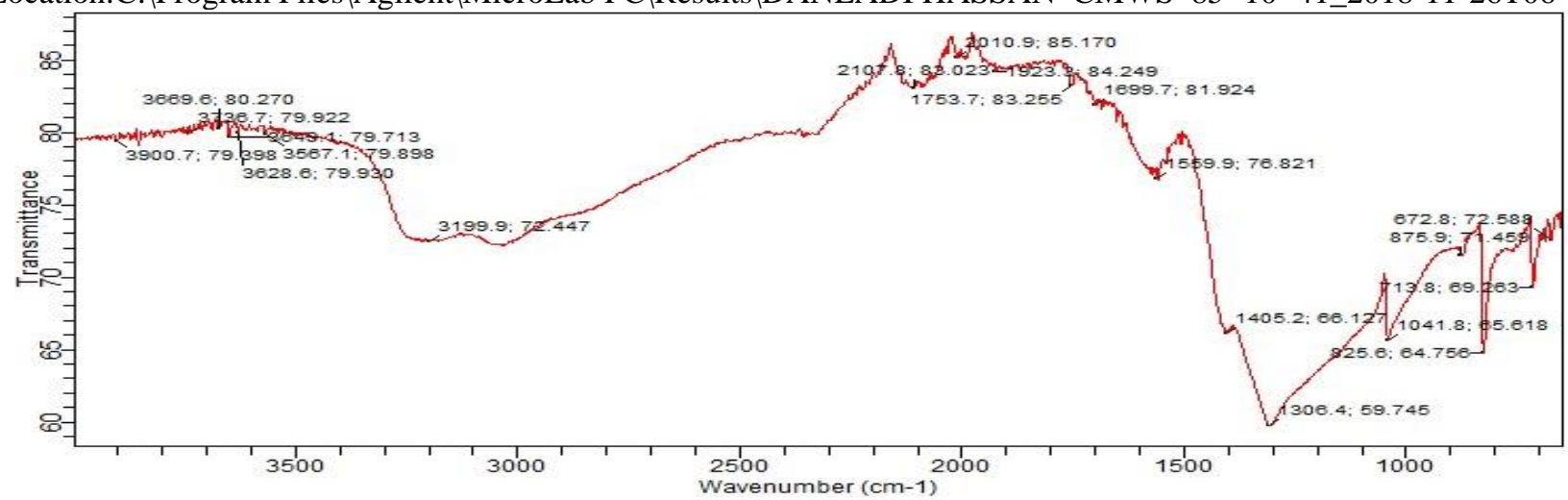

Fig 3: FTIR Spectral of Explosives Sample of AMWS, BMWS and CMWS Agilent Technologies

Sample ID:DANLADI HASSAN AMWGA 65- 20- Method Name:Transmittance12-3

Date/Time:2018-11-26T07:49:39.544-08:00

File Location:C:IProgram Files\Agilent|MicroLab PCIResultsIDANLADI HASSAN AMWGA 65- 20- 123_2018-11-26T07-4939.a2r 


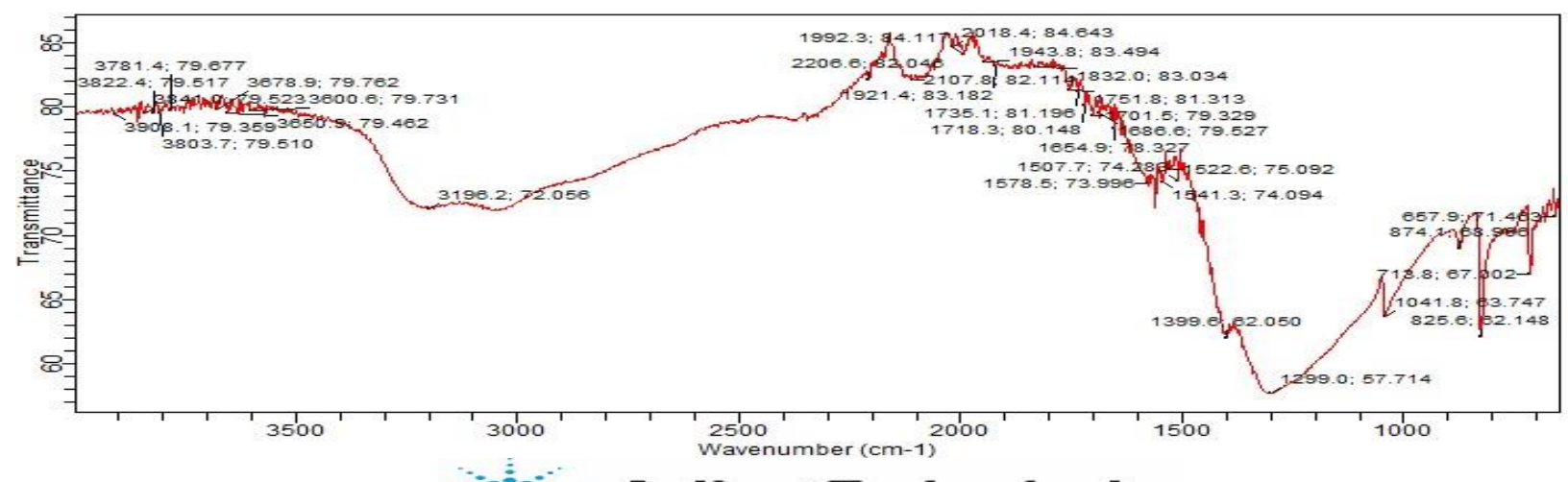

Sample ID:DANLADI HASSAN BMWGA 80- 16- Method Name:Transmittance 2-2

Date/Time:2018-11-26T07:15:40.428-08:00

File Location:C:\Program Files\Agilent\MicroLab PC\Results\DANLADI HASSAN BMWGA 80- 16- 22_2018-11-26T07-15-40.a2r

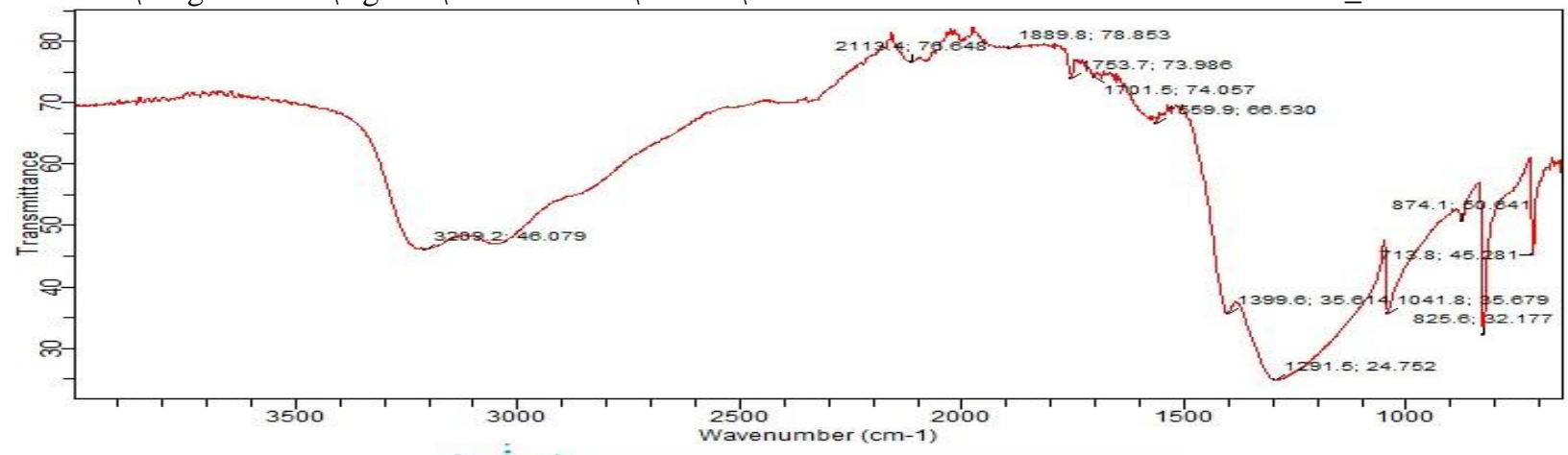

Agilent Technologies

Sample ID:DANLADI HASSAN CMWGA 85- 10- Method Name:Transmittance 4-1

Date/Time:2018-11-26T06:30:06.788-08:00

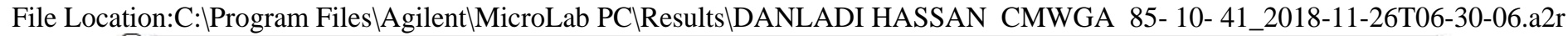

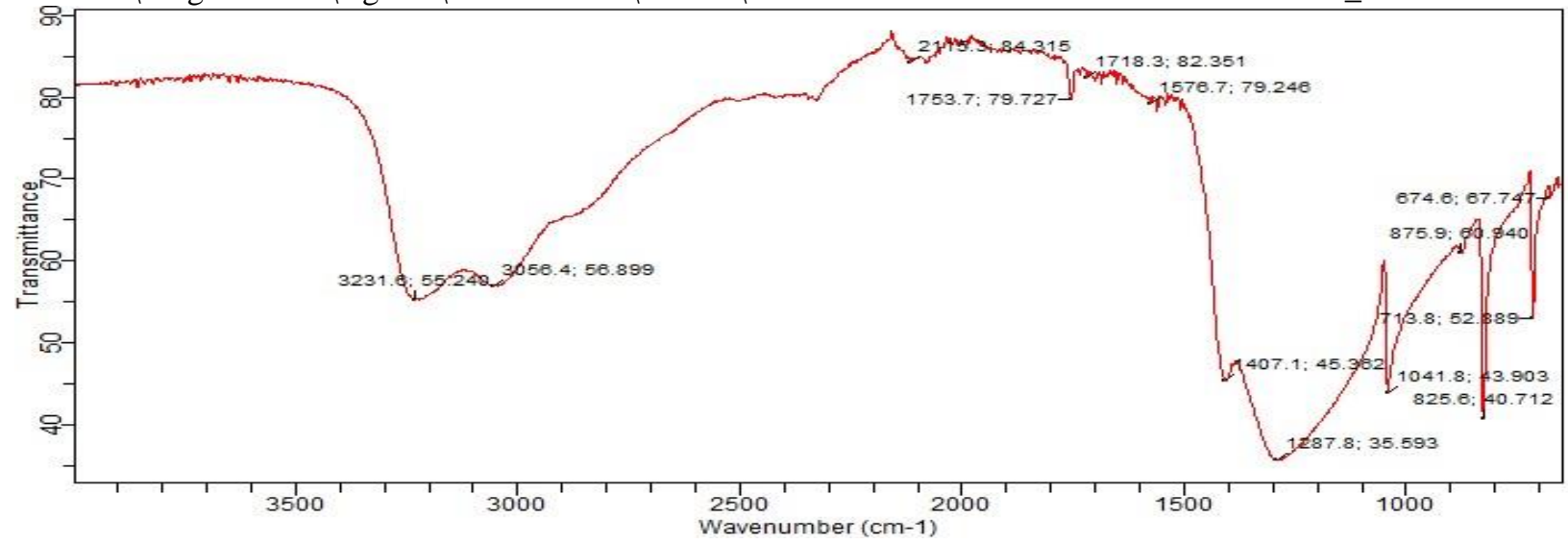

Fig 4: FTIR Spectral of Explosives Samples of AMWGA, BMWGA andCMWGA

\section{Scanning Electron Microscope (SEM)}

The SEM image of formulated explosives from Palm Kernel Shell (APKS, BPKS, CPKS, APKGA, BPKGA and CPKGA) exhibited morphological characteristics of crater type with tiny holes, crack at the surface, white spheroidal substances and scraggy as indicated in Fig 5 and Fig 6 . The clusters exhibited by the formulated explosives were indicative of homogenized mixture of ammonium nitrate (AN), Biomass, Sulphur and Binders with dimensions ranging from $58.3 \mu \mathrm{m}-4.75 \mu \mathrm{m}$. The images and dimensions observed in this study agreed with the
SEM results of Anniyapan et al (2006) in the synthesis and characterization of 1,1diamino 2,2dinitroethylene.

The SEM image formulated explosives from Malaina wood (AMWS, BMWS, CMWS, AMWGA, BMWGA and CMWGA) exhibited morphological characteristics of honey comb shape at various sizes, white spheroidal uneven shape, scraggy and flaky shape with smooth surfaces as indicated in Fig 7 and Fig 8 . Clusters were observed in all the samples which were identified as the results of the interaction of the AN, Biomass, Sulphur and the binders used. The formulated samples dimensions ranges from 
$44.6 \mu \mathrm{m}-5.89 \mu \mathrm{m}$. The SEM morphology and dimensions observed in this study agrees with the findings of Beckstead
(2007) in his study of modeling of combustion and ignition of explosives ingredients.

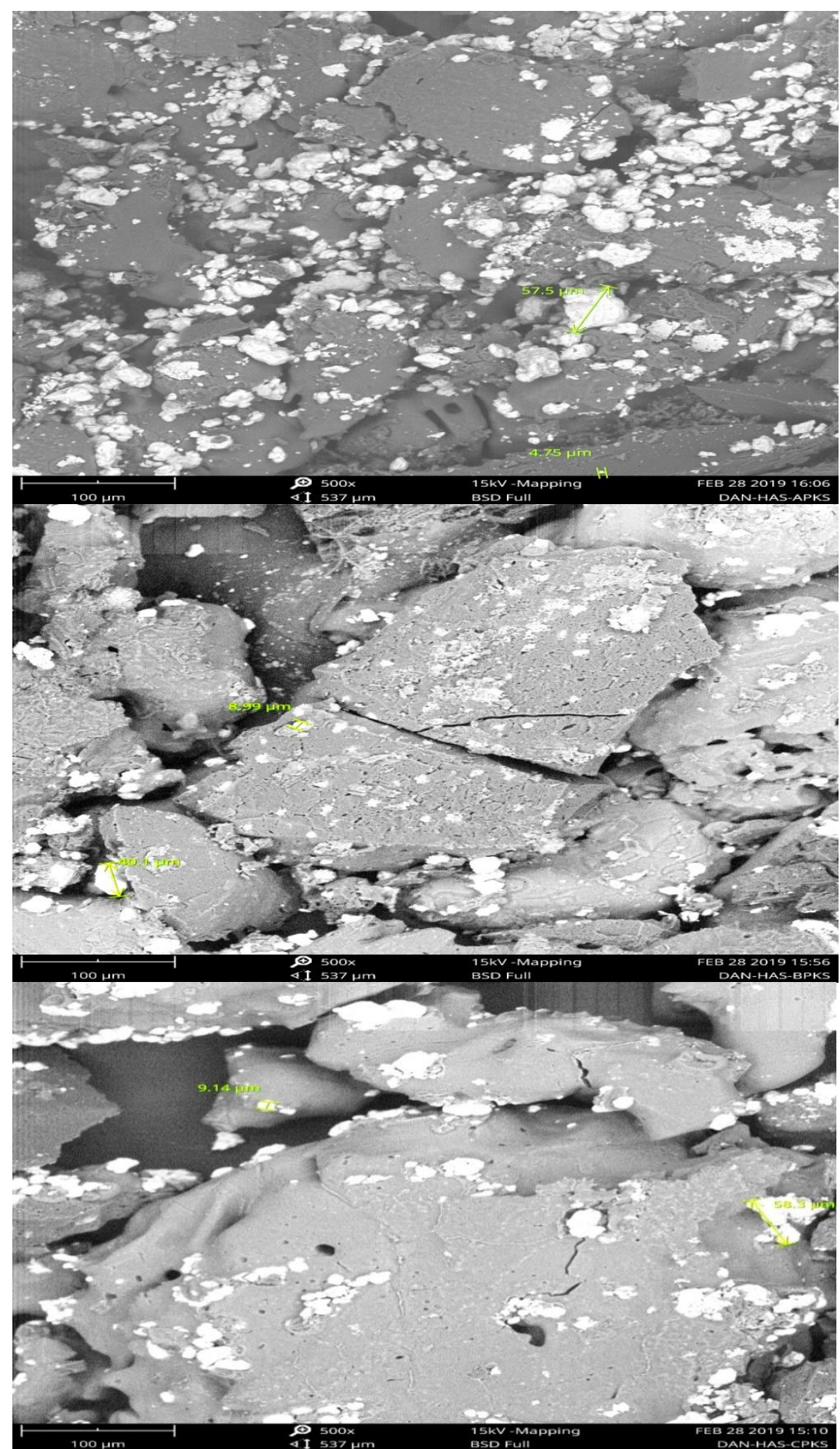

Fig 5: SEM Image, Morphology of Samples APKS, BPKS, CPKS.

\section{APKS}

\section{BPKS}

\section{CPKS}




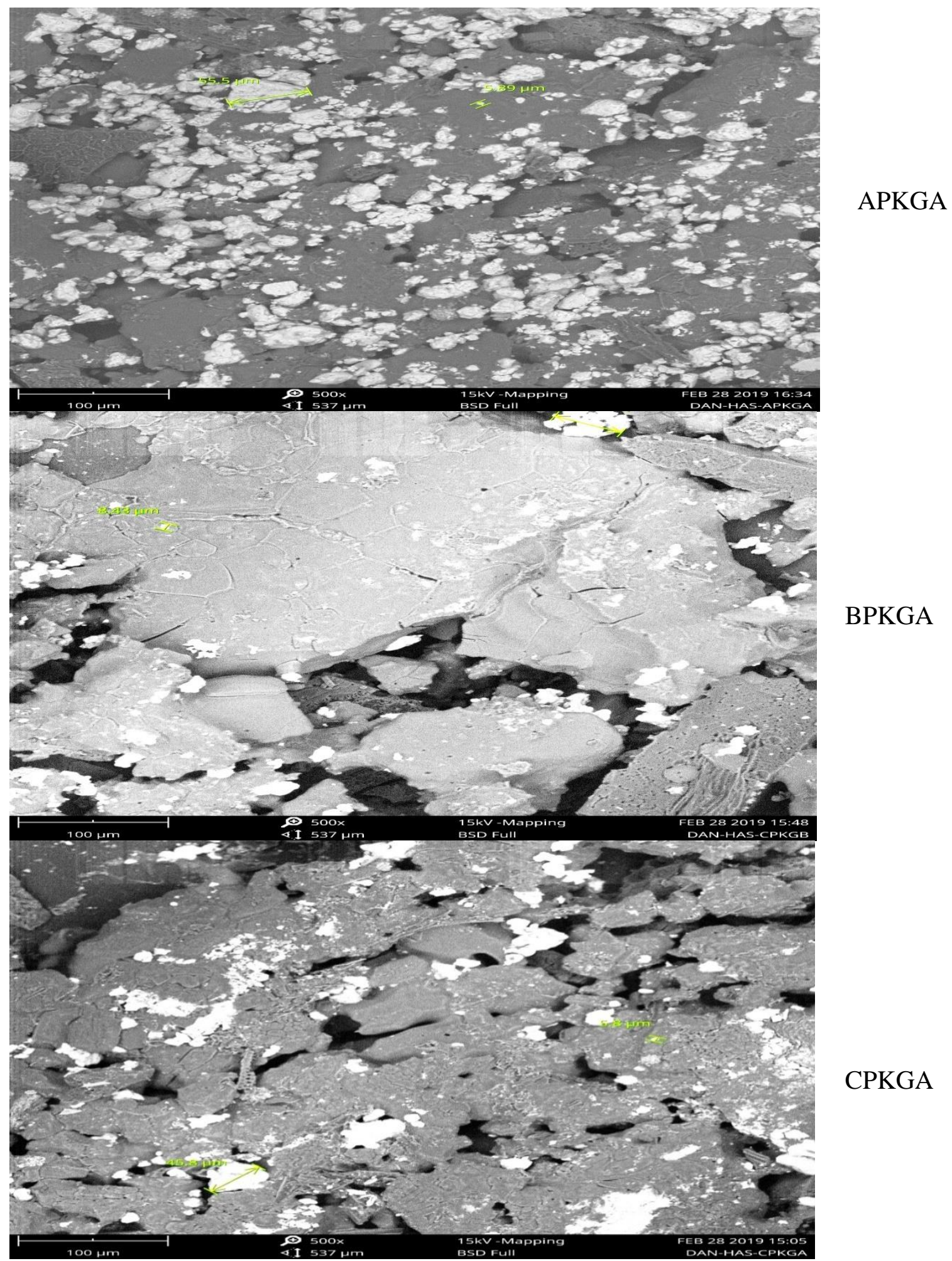

Fig 6: SEM Image, Morphology of Samples APKGA, BPKGA and CPKGA. 


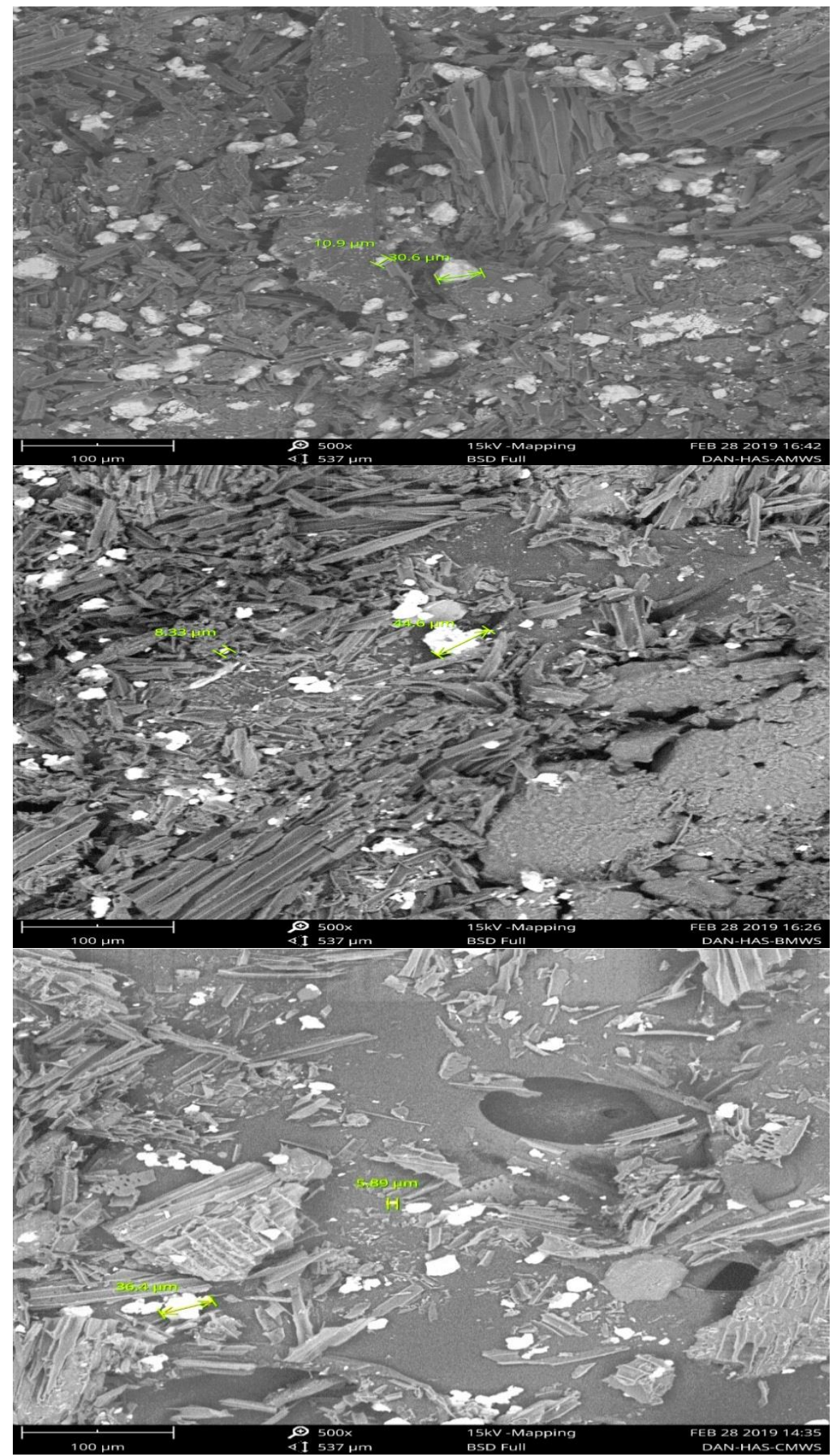

AMWS

BMWS

CMWS

Fig 7: SEM Image, Morphology of Samples AMWS, BMWS and CMWS 


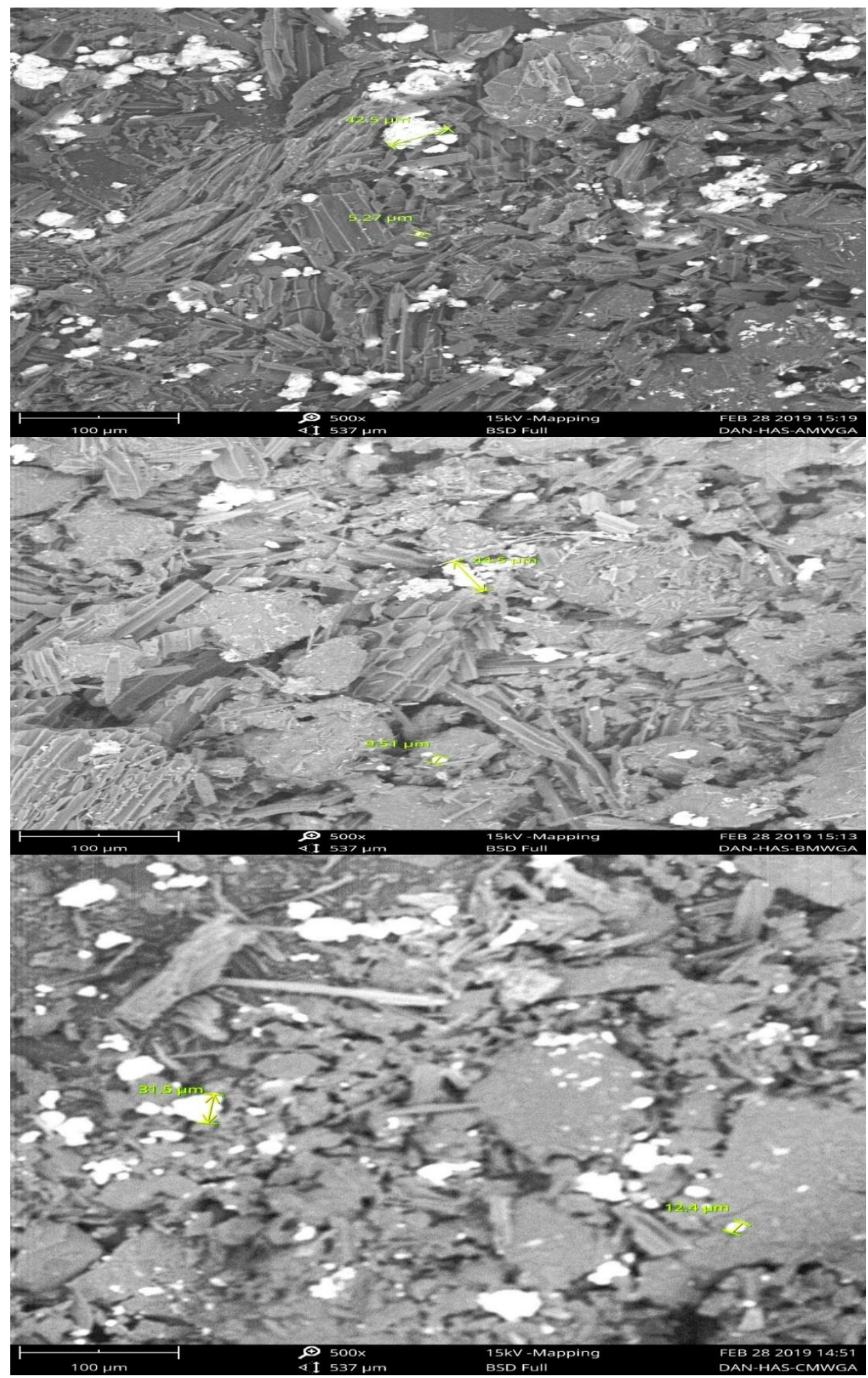

AMWGA

BMWGA

\section{CMWGA}

Fig 8: SEM Image, Morphology of Samples AMWGA, BMWGA and CMWGA

\section{Differential Scanning Calorimeter (DSC)}

DSC results shows formulated explosives of APKS, BPKS and CPKS (Fig 9) displayed a first stage curve of endothermic values of $90-100 ; 130-140 ; 170-180{ }^{\circ} \mathrm{C}, 45-84 ; 130-170{ }^{\circ} \mathrm{C}$ and 45-54; 70-90; $130-170{ }^{\circ} \mathrm{C}$ indicating the phase change gradually from the lower temperature and melting at the highest endothermic temperature for the samples respectively before combustion at the high peak temperature of exothermic value of $241.78,168.54{ }^{\circ} \mathrm{C}$ and $212.78{ }^{\circ} \mathrm{C}$ for APKS, BPKS and CPKS respectively. While formulated explosives of APKGA, BPKGA and CPKGA as shown in Fig 10 also displayed a curve of first stage for an endothermic values of $120-130 ; 160-170 ; 180{ }^{\circ} \mathrm{C}, 45-128{ }^{\circ} \mathrm{C}$ and 40-129-169 ${ }^{\circ} \mathrm{C}$ which indicates the phase change gradually melting from the lower temperature and melted at the highest 
endothermic temperature for the samples respectively before combustion at the high peak temperature of exothermic value 241.78, 250.20 and $203.62{ }^{\circ} \mathrm{C}$ for APKGA, BPKGA and CPKGA respectively.

DSC results for formulated explosives of AMWS, BMWS and CMWS (Fig 11) displayed a first stage curve of endothermic values of 50,$92 ; 130-162{ }^{\circ} \mathrm{C}$ and $90:-190{ }^{\circ} \mathrm{C}$ respectively and which also explains the gradual phase change from the lower temperature and melting at the highest endothermic temperature for the samples respectively before combustion at the high peak temperature of exothermic values of $181.64,184.97$ and $196.19{ }^{\circ} \mathrm{C}$ for AMWS, BMWS and CMWS respectively.

DSC results for formulated low explosives of AMWGA, BMWGA and CMWGA (Fig 12) displayed a curve of endothermic values of 130,130 and $170{ }^{\circ} \mathrm{C}$ respectively for the 3 samples indicating the phase transition from the lower temperature to high endothermic temperatures and $170{ }^{\circ} \mathrm{C}$ for the samples respectively, before combustion at the highest peak temperature of exothermic values of $191.29,189.13$ and $184.86{ }^{\circ} \mathrm{C}$ for AMWGA,
BMWGA and CMWGA. All values obtained were close to the values of Moulai et al, (2016) who worked on the synthesis of two blends of non- crystalline binder based low explosives using butyl nitroxy ethylamine binder. The curve observed for explosive mix 1 and mix 2 indicated several peaks of either endothermic or exothermic reactions with both samples displaying three endothermic peaks after the temperature value of $150^{\circ} \mathrm{C}$. Consequently, it also gave exothermic values of 199 and $210^{\circ} \mathrm{C}$ for mix 1 and mix 2 explosives.

The DSC results indicated that all the formulated explosives displayed slightly similar trend and values in the endothermic peaks which explains that all have a close similar phase change transition. Similarly, the low explosive with the starch as binder displayed a slightly lower exothermic value than those with gum arabic as binder. This trend could be as a result of the gum arabic being a better secondary fuel that absorbed the excess oxygen to combust better, yielding higher values than the starch.

\section{^exo}

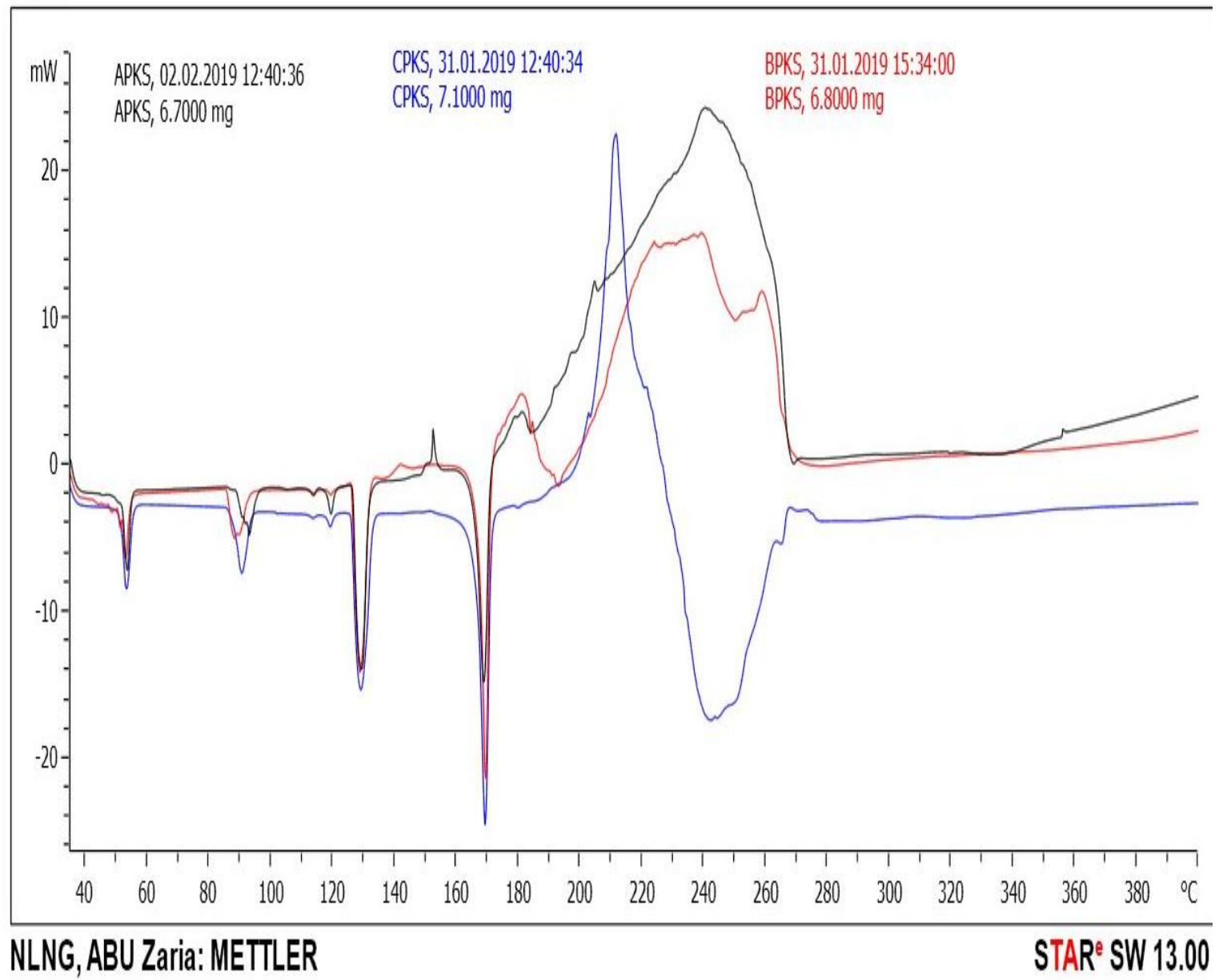

Blue: CPKS, Red: BPKS

KEY: Black: APKS,

Fig 9: DSC Curve of APKS, BPKS and CPKS 


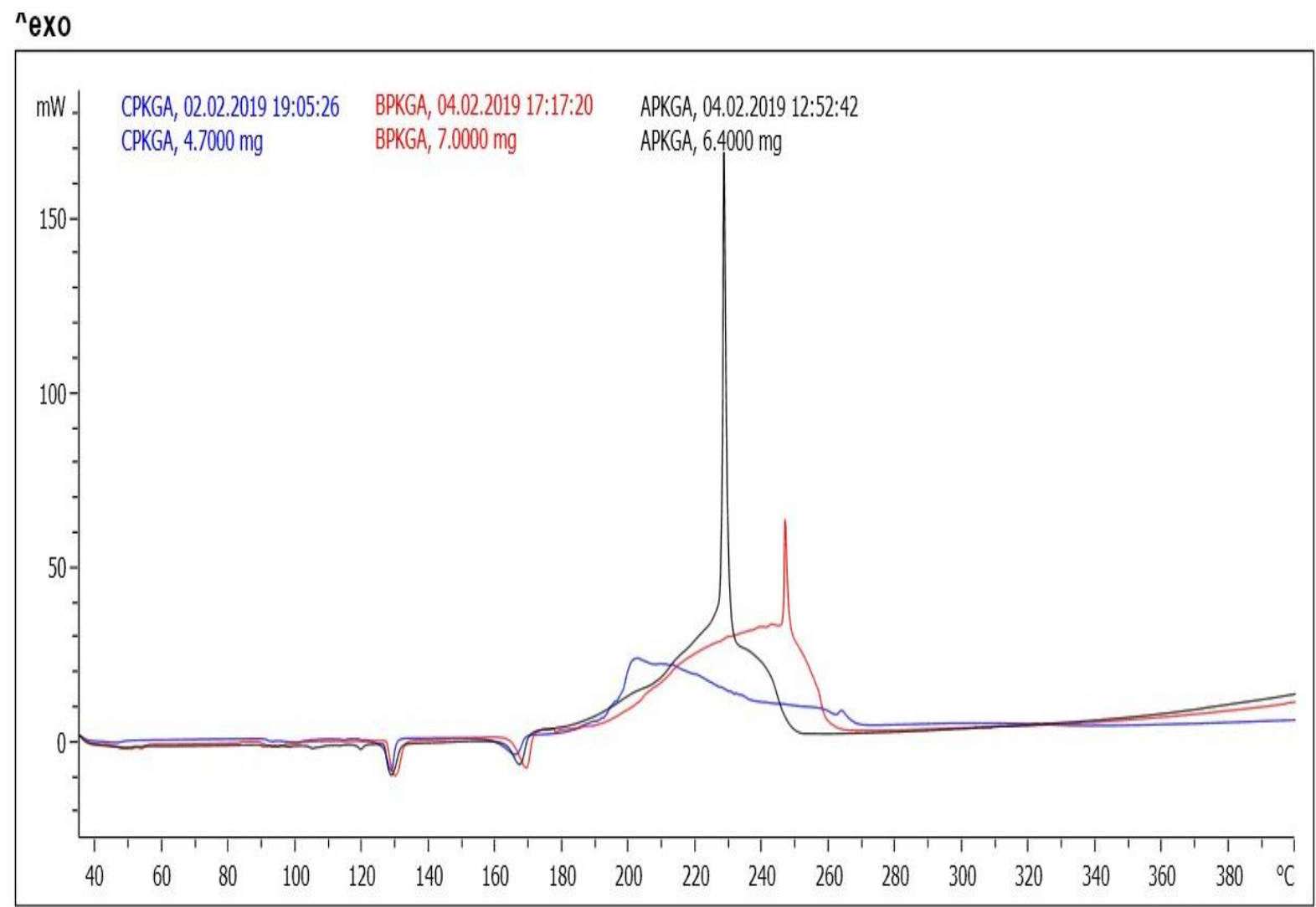

NLNG, ABU Zaria: METTLER

STARe SW 13.00 


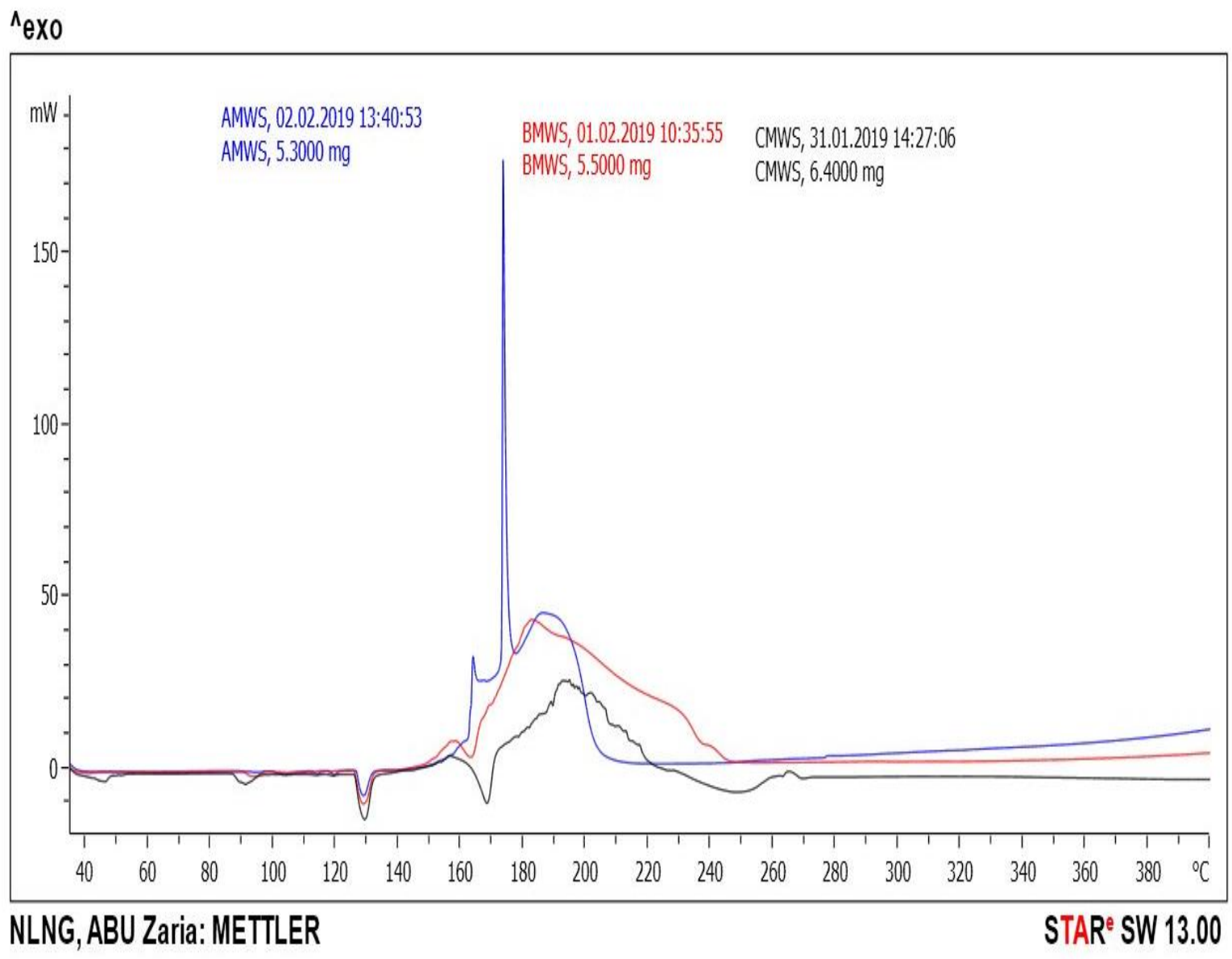

KEY: Black: CMWS,

Blue: AMWS,

Red: BMWS

Fig 11: DSC Curve of AMWS, BMWS and CMWS 


\section{AeXo}

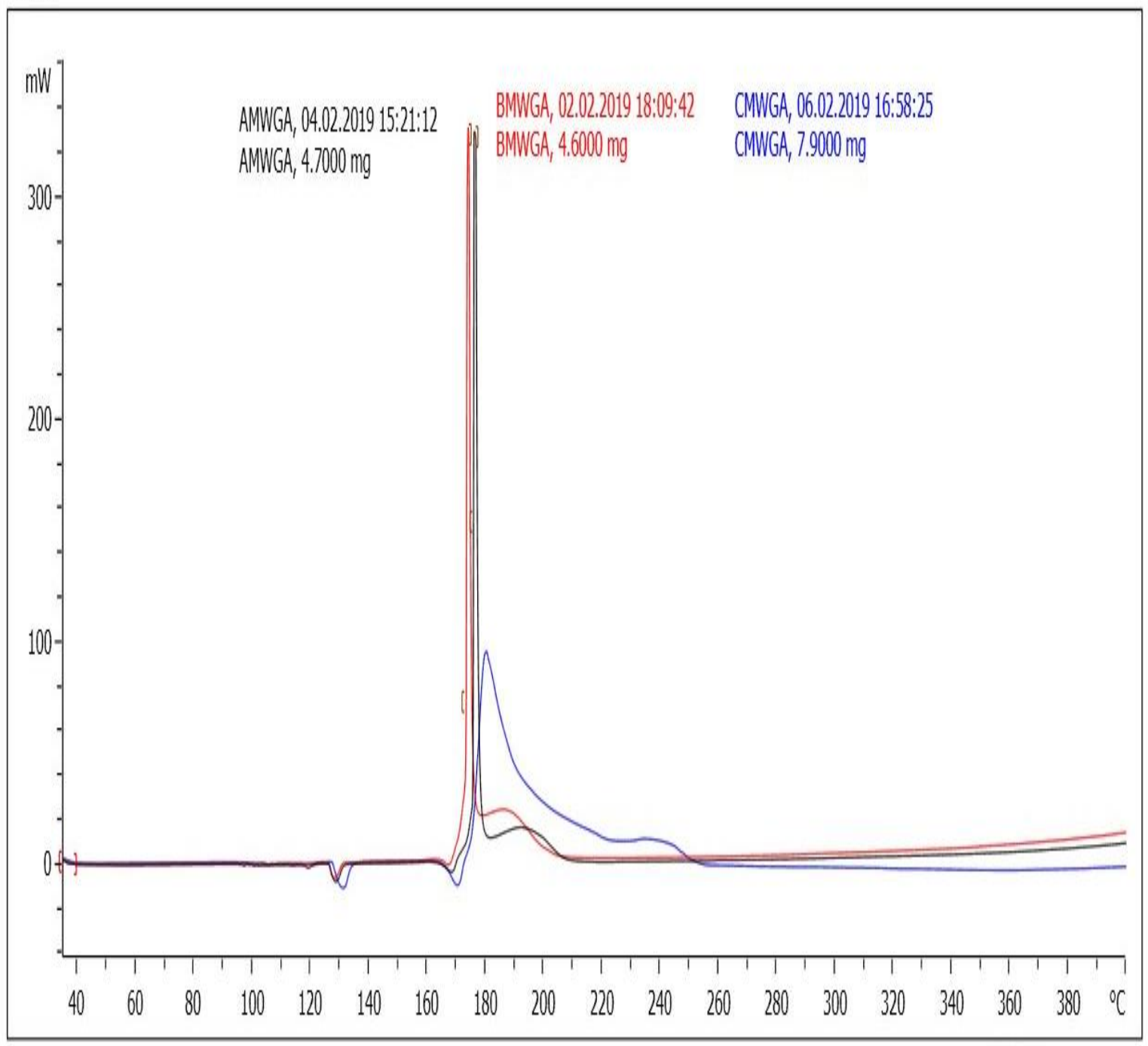

NLNG,ABU Zaria:METLLER

STAR SW 13.00

KEY: Black: AMWGA, Red: BMWGA, Blue: CMWGA

Fig12: DSC Curve of AMWGA, BMWGA and CMWGA 


\section{ROCKET TESTING}

The rockets designed were tested at Research and Development Center Field of Defence Industry Corporation of Nigeria (DICON) and from the results, it was observed that the formulated explosives made from APKGA, BPKGA and AMWS plant biomass gave better performance in terms of thrust and distance covered of $588 \mathrm{~m}, 521 \mathrm{~m}$ and $250 \mathrm{~m}$ respectively. However, the formulated explosives made from APKS, BPKS and BMWS plant biomass did not actually lift off but burnt on the ground haphazardly covering distances of $8 \mathrm{~m}, 11 \mathrm{~m}$ and $17 \mathrm{~m}$ respectively. The results indicated that the explosives were effective in projecting the rockets with few having some limited performance. The low explosives could be put into use depending on the desired usage.

\section{CONCLUSION}

The low explosive propellants were formulated using plant biomass obtained from Palm kernel shell and Malaina wood as sources of carbon. The explosives made from Malaina wood were solid black powder with porous white patches, dark brownish and soft while that of Palm kernel shellwere hard, black grayish, homogenous powder and light grey. The FTIR result revealed that all the low explosives exhibited different vibrational stretchings such as $\mathrm{N}-\mathrm{H}, \mathrm{O}-\mathrm{H}, \mathrm{C}=\mathrm{O}, \mathrm{N}-\mathrm{O}$ and $\mathrm{C}-\mathrm{H}$ among other vibrations of different functional groups within spectral ranges from 3908.1 $\mathrm{cm}^{-1}-674,6 \mathrm{~cm}^{-1}$. The presence of these functional groups of Isothiocynate, Amines, Alkenes Alcohols, Nitro groups and Esters thus, confirmed the formation low explosives. SEM analysis of the low explosives revealed shapes of crater, honey comb, scraggy, flaky, rhombic and fiber like stripes with ranges from $58.3 \mu \mathrm{m}-$ $4.75 \mu \mathrm{m}$ which are morphological features of low explosive materials. From the DSC results, the endothermic peaks range from $70-160{ }^{\circ} \mathrm{C}$ and exothermic peaks range of $210-260{ }^{\circ} \mathrm{C}$ indicating a transition change from lower temperature and melting at the highest temperature and thus indicating the burning ability of the explosive in space. From the rocket testing, it was observed that the explosives obtained from APKGA, BPKGA and AMWS gave better performance in terms of thrust and distances covered of $588 \mathrm{~m}, 521 \mathrm{~m}$ and $250 \mathrm{~m}$ respectively. However, APKS, BPKS and BMWS did not actually lift off but burnt on the ground haphazardly covering distances of $8 \mathrm{~m}, 11 \mathrm{~m}$ and $17 \mathrm{~m}$ respectively, however, all the low explosives formulated can be used based on the choice of distances needed to cover.

\section{REFERENCES}

[1] Anniyappan, M., Talawar, M.B., Gore, GM., Venagopalan, S., and Ghande, B.R.,(2006),
[2] Synthesis Characterisation and Thermolysis of 1,1-diamino 2,2dinitroethylene

[3] (FOX-7) and its Salt, Journal of Hazardous Materials. 137(2):812-819.

[4] Beckstead, M.W., and McCarty, K.P., (1982). Modeling Calculations for HMX Composite Propellant ,American Institute of Aeronautics and Astronautics Journal, 1. (20): 106-115.

[5] Beckstead, M.W., Puduppakkam, K., Thakre, P. and Yang, V. (2007). Modeling of combustion

[6] and ignition of solid-propellant ingredients. Prog. Energy Combust. Sci., 33(6), 497-551.

[7] Cohen, N.S., (1997). Review of Composite Propellant Burn Rate Modeling, AIAA Journal, 3. (18): 277-293.

[8] Cohen, N.S., and Strand, L.D., (1981).An Improved Model for the Combustion of AP Composite Propellants, paper 81-1553, 17th Propulsion Conference.

[9] Daintith, J. (2000). Oxford Dictionary of Chemistry, 4th Ed. Oxford University Press, New York, USA.146-149.

[10] David, W., Rutherford., Robert L. Wershaw., and Larry G. Cox., (2014).Changes in Composition and Porosity Occurring During the Thermal Degradation of Wood and Wood Components,Scientific Investigations Report 2004-5292.

[11] Gordana, S.U., Mohammed, M.Z., and Dusan, Z. M., (2006). Investigation of the interfacial bonding in Composite Propellant. 1,3,5- Trisubstituted Isocyanurates as Universal Bonding Agents. Journal Serbia Chemical Society. 71(5) 445-458.

[12] Jai, P.A.,(2010). High Energy Materials: Propellants Explosives and pyrotechnics, 218-219, 2nd edition, Willey-vchverlag.

[13] Kevin, G., (1986). Ordnance Technology, Indian Journal of Naval Sea System Command. Vol.40, 1-23.

[14] Lostoski M.R, Szucs J and Schwening M. (2016): Structural Design and Fabrication of Rockets, Honors Research Project, 387.

[15] Moulai, K.B., Mitche, L., Laurence, J., and Alain, D., (2016). Temperature Sensitivity of Propellant Combustion and Temperature Coefficient of Gun Performance.Central European Journal of Energetic Materials, 13(40:10051026.

[16] Niklos, W., (2004). Improving the Mechanical Properties of Composite Rocket Propellant, a Paper Presented at Department of Fibre and Polymer Technology Royal Institute of Technology, Stockholm. $1-6,283-287$.

[17] Norman G,J (1998).Explosives chemical product, explosive department, Du pont de Nemours, Willinton, Delaware, 1960- 67

[18] Rodrigo I.C., John M.B., and Esam K., (2005). Characterization and Thermal Decomposition Studies of a Hydroxy Terminated Rocket (HTPE) Copolymer and Binder for Composite Rocket Propellant. Academic Journal of Composite Propellants, Cranfield University, Shrivenham, Swidon SN68LA United Kingdom, 221-301.

[19] Tenny, L.D., (1998).The Chemistry of Powder and Explosives .Angrif Press, Las Vegas, Navada, 195-214, 256-267.

\section{AUTHORS}

First Author - OA Babatunde, Department Of Chemistry, Nigerian Defence Academy (NDA) Kaduna

Second Author - DR Hassan, Department Of Chemistry, Nigerian Defence Academy (NDA) Kaduna

Third Author - MM Namadi, Department Of Chemistry, Nigerian Defence Academy (NDA) Kaduna 